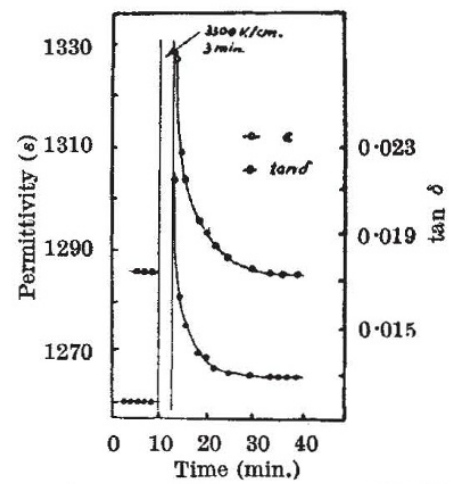

Fig. 1. SAMPLE $A$ : TEMP. $24^{\circ}$ C. ; D.C. FIKLD, 3300 V./OM., APPLTHD FOR 3 MIN.

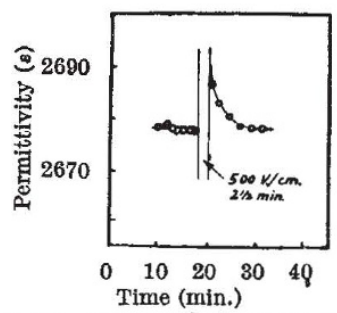

Fig. 2. SAMPLE $B$ : TEMP. $24^{\circ}$ C.; D.c. FIELD, 500 V./OM., APPLIED FOR $2 \frac{1}{2}$ AITN.

of the same type were observed at temperatures corresponding to the portion of the plateau in the permittivity - temperature curve in which the temperature coefficient is slightly negative (that is, between $20^{\circ}$ and $45^{\circ} \mathrm{C}$.), and in the regions where the coefficient is positive. The dielectric losses and permittivity in each case varied in a similar manner, approaching very nearly their original value after a period of 10-50 $\mathrm{min}$.

At temperatures above $T_{\operatorname{smax}}$, the permittivity was smaller immediately after the cessation of tension and reverted slowly to its original value, the effect being largest in the case of higher tensions and prolonged periods of application. Figs. 3 and 4 show typical curves obtained for sample $C$ consisting of

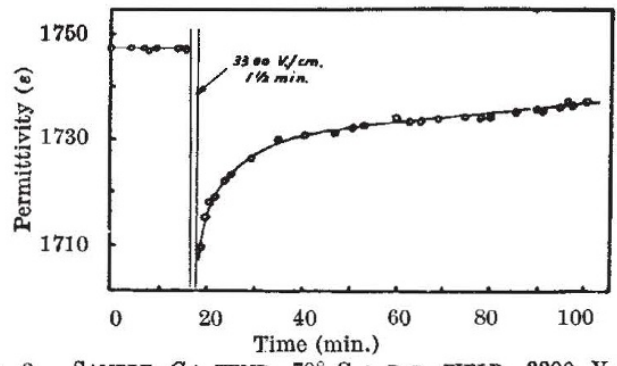

Fig. 3. Sample $C$ : TEMP. $70^{\circ}$ C.; D.c. Finld, 3300 V./OM.,

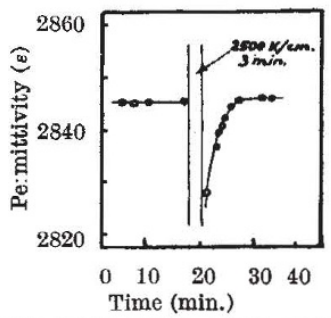
Fig. 4. SAMPLE $B$ : TEMP. $80^{\circ}$ C. ; D.C. FTELD, 2500 V./OM.,
APPLIED -FOR 3 MIN. barium strontium titanate $\left(\mathrm{BaTiO}_{3}: \mathrm{SrTiO}_{3}=75: 25\right.$, by weight ; $T_{\operatorname{smax}}: 21 \cdot 5^{\circ}$ C.), and sample $B\left(T_{\text {smax }}\right.$ : $50^{\circ}$ C.). Analogous results were obtained with all the compositions examined, the only exception being sample $C$ at a temperature just above $T_{\text {max }}$, which showed a temporary increase in permittivity. The loss tangent, being low beyond $T_{\text {smax }}$, remained constant at a value of 0.0025 and 0.001 in the case of samples $B$ and $C$, respectively.

It is seen that, within the temperature range corresponding to the distorted perovskite structure, a temporary increase in permittivity was obtained, while in the region of the cubic structure a temporary decrease was generally observed. A possible explanation for the increase at a temperature just above $T_{\text {smax }}$ in the case of sample $C$ may be that the two structures co-exist within a temperature range extending slightly beyond $T_{\mathrm{smax}^{3,4}}$, the effect due to the distorted structure being the larger one.

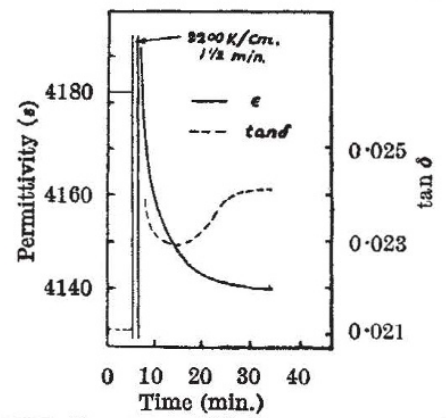

Fig. 5. SaMple $D$ : TTEMP. $30^{\circ}$ C.; D.0. FLELD, 2200 V./OM. APPLIED for 1t MIN.

At a temporature below $T_{\text {smax }}$, a third effect was observed in the case of some compositions after the application of tensions higher than those resulting in the temporary increase in the permittivity only. Under these conditions, the permittivity approached asymptotically an apparently permanent lower value. Fig. 5 shows this effect, combined with the initial temporary increase, for sample $D$ having a permittivity maximum at $50^{\circ} \mathrm{C}$.

A fuller account of the work will be published later.

We are greatly indebted to the United Insulator Co., Ltd., Surbiton, for generously giving us facilitios in their Research Laboratory.

${ }^{1}$ J. Phys., U.S.S.R., 10, 95 (1946).

Ind. Eng. Chem., 38, 1097 (1946).

Trans. Farad. Soc., 42, 224 (1946).

'Nature, 160, 58 (1947).

\section{INTERNATIONAL TIMBER CONFERENCE}

A REPORT has been issued of the International A Conference on Timber held at Marianski Lazne, Czechoslovakia, during April 28-May 10, 1947, under the auspices of the Food and Agricultural Organisation of the United Nations (Washington, D.C. : Food and Agriculture Organisation. 50 cents). These discussions, the first comprehensive discussions of timber and forestry to be held in Europe since the end of the War, have shown that the nations represented were in unanimous agreement on a variety of issues. The Conference did not attempt to solve all the problems of forests and timber in Europe, but con- 
fined its attention to more limited objectives and admitted that, even with respect to these, its recommendations were only a starting point.

It is well known that post-war Europe is confronted with a grave timber problem. It is not a matter, as some appear to think, of merely seeking out accessible sources of supply and cutting the forests down. The large excess fellings and destruction committed during the War has led to a serious position in parts of Europe and outside Europe. Excess fellings cutting out more than the annual increment of one or more years-means in the end the disappearance of a forest. Even to supply the well-known needs for timber of large populations we should not be justified in dooming forests which should be maintained in the interests of posterity and often for reasons quite other than timber alone.

For Europe alone it was known that more timber annually is required than pre-war Europe used; yet the soft-wood timber supplies are below the average of the year before 1939. This is delaying reconstruction. Methods of bridging the gap, it was realized, appeared to be not only inadequate but also difficult to achieve ; there was also the fear that repercussions might lead to an even more serious crisis in the future; in other words, overcutting after the drain imposed on the coniferous forests during the War might lead to lasting damage to the surviving European forests. The second alternative appeared equally difficult : a reduction in timber consumption was equally undesirable, since it is in apparent conflict with improvement in housing and living standards which has been adopted as a primary objective by the United Nations Organisation. The Conference approached this matter by dividing it into three parts: (1) short-term problems; (2) longterm problems; and (3) further procedure; and the three chapters of the report deal with the problems in this manner.

The Belgian delegate reported on savings effected by substituting other materials for lumber. A memorandum was submitted by the United Kingdom on economy and the uses of timber, including restrictions and the fixing of maximum sizes in which timber is to be used for joists, rafters, floorboards and so forth. Some of these restricted efforts, it may be said, have not proved very satisfactory, and do not help in reconstruction on the countryside.

A note had been drawn up by the Food and Agriculture Organisation Preparatory Commission on World Food Proposals, and briefly this report stated that the timber situation presents the same problem which has confronted the Commission in regard to several other commodities with, says the report, "the important difference that as food scarcities begin to subside, the world-wide timber shortage is becoming more serious".

It is suggested in the present report that a better organisation for distribution and allocation, by transport and credit facilities, would assist in some degree; the introduction of technical improvements in order to ensure better utilization of available timber supplies would also be valuable.

There is another resolution submitted by the Economic and Social Council of the United Nations, recognizing the seriousness of the present timber shortage in Europe which threatens to delay economic recovery, and this resolution welcomes the initiative taken by the Food and Agriculture Organisation. It is not possible here to deal in detail with all the resolutions and recommendations adopted by the
Conference; but briefly they refer to various details in forest management and to the necessity for dealing with the world-wide shortage of timber in such a manner that serious depredations will not be made on the forests, which would result in their destruction. It is also recommended that proper organisation and proper technical methods should be introduced into the management of forests, and having regard to the long period required for the development of forest resources and for the fulfilment of domestic rational forest policies, it is considered desirable "that the European countries concerned should meet together from time to time to exchange information and views about their problems in the field of medium- and longterm forestry. F.A.O. under its existing mandate is able to call together consultative committees, and it would seem appropriate therefore that F.A.O. should consider providing such a committee on forestry within its framework. It could meet from time to time as might seem necessary in the opinion of F.A.O. and of the governments concerned acting in close consultation." E. P. StebBING

\section{SCIENTIFIC APPROACH TO THE LACE INDUSTRY}

$\mathbf{T}$ its treatment of scientific and technical research and development, the report of the Board of Trade Working Party on the Lace Industry*, of which Miss L. S. Sutherland was chairman and the late Prof. J. M. Gulland a member, follows similar lines to earlier reports from 'working parties' dealing with other textile industries. Like most of the latter, the machine-lace industry grew out of a craft, that of traditional hand-lace, and was not born of scientific research. In addition, it has always been, and still is, essentially a cotton industry, and in its essentials the industry remains the same as in the days of our grandfathers.

Speaking in very broad terms, in the past the lace industry in Britain has shown little interest in research. The total expenditure by individual firms on research appears to be small, and contribution to co-operative research by membership of research institutes such as the British Cotton Industry Research Association was by no means universal although fairly common. In spite of signs of a changing attitude in recent years, the 'working party' attributes many of the present urgent problems of the industry to its failure over a long period to investigate systematically and scientifically the textile, engineering and other aspects of the trade, not least important being those affecting health. One of the strongest recommendations in the report is, in fact, that the newly formed Research Council for the industry should press forward its investigations into a satisfactory substitute for graphite, the use of which as a lubricant for lace machines has given the machine-holding sections the character of a 'dirty trade'.

In characterizing the lace industry as a whole with indifference to research, with neglect of fundamental research and with a marked tendency for whatever research is prosecuted to be sporadic, and noting the absence of research staff and, excejpt in the dressing section, even of scientific staff, the 'working party' frankly recognizes that no industry could achieve

*Board of Trade. Working Party Reports : The Lace Industry. (London: H.M. Stationery Offee, 1947.) 38. 6 d. net. 